Results A total of 1,095 newborns were included. Within the first $24 \mathrm{~h}, 99.2 \%$ and $90.4 \%$ of the newborns passed their first meconium/ stool and first urine, respectively. The number of meconium/stool and voidings was higher in the CS group. The number of meconium/stools within the first $24 \mathrm{~h}$ was higher in exclusively breastfed newborns. Combination-fed newborns and newborns with a lower birth weight had a higher number of voidings. The number of meconium/stools in the first $24 \mathrm{~h}$ was significantly lower in newborns weighing $<2,500 \mathrm{~g}$. Furthermore, breast feeding frequency correlated with the number of meconium/stools and voidings at all time points.

Conclusions The results of this study show that the mode of delivery, birth weight and feeding method and frequency and may influence meconium/stool and urinary patterns in newborns.

\section{PERINATAL AND NEONATAL OUTCOMES IN MULTIPLE PREGNANCIES: ASSISTED REPRODUCTION VERSUS SPONTANEOUS CONCEPTION}

doi:10.1136/archdischild-2012-302724.1361

B Mutlu, HG Kanmaz, SS Oguz, 0 Erdeve, N Uras, U Dilmen. Neonatal Intensive Care Unit, Zekai Tahir Burak Maternity Teaching Hospital, Ankara, Turkey

Background Studies comparing perinatal outcomes in multiples conceived following the use of artificial reproductive technologies (ART) vs. spontaneous conception (SC) have reported conflicting results in terms of mortality and morbidity. The objective of our study was to compare perinatal and neonatal outcomes of multiplets born after artificial reproductive technology (ART) and spontaneous conception (SC).

Methods Three hundred and sixty seven neonates born after SC and 596 after ART were studied. Maternal characteristics, neonatal characteristics, neonatal morbidities and mortality were assessed between two groups.

Results The duration of pregnancy was significantly shorter in ART group (32.6 \pm 4.0 vs $34.2 \pm 3.2, \mathrm{p}<0.001)$. The mean birth weight in the ART group was significantly lower when compared with control group ( $1892 \pm 690$ vs $2112 \pm 602, \mathrm{p}<0.001)$. The number of perinatal and neonatal deaths (9.5 vs $2.7 \%, \mathrm{p}<0.001$ and 1.7 vs $1 \%$, $\mathrm{p}<0.001)$ were significantly higher in the ART group. The incidence of intraventricular hemorrhage (63.7 vs $52.8 \%, \mathrm{p}<0.05$ ), anemia (26.6 vs $16.5 \%$, $\mathrm{p}<0.05$ ), sepsis ( 22.3 vs $14.6 \%$, $\mathrm{p}<0.05$ ), bronchopulmonary displasia (7.1 vs $1.8 \%, \mathrm{p}<0.05)$, retinopathy of prematurity (24 vs $16.1 \%, p<0.05$ ) were significantly higher in the study group. Conclusion Multiple pregnancies achieved with ART are at greater risk for obstetric complications and adverse neonatal outcome in comparison with naturally conceived multiple pregnancies.

\section{PREVALENCE AND OUTCOME OF HIGHER ORDER MULTIPLE PREGNANCIES IN LAGOS, NIGERIA}

doi:10.1136/archdischild-2012-302724.1362

IB Fajolu, VC Ezeaka, EO Iroha, MTC Egri-Okwaji. Paediatrics, College of Medicine University of Lagos, Lagos, Nigeria

Background and Aims Higher order multiple (HOM) pregnancies are associated with higher risk of complications for both mother and babies with resultant increase in financial and psychological strain on the families. Data on outcome is essential for adequate counseling of families and positive interventions.

Aim To determine the prevalence and outcome of HOM pregnancies in a tertiary hospital in Lagos, Nigeria.

Methodology Data on the mode of delivery, gestational age, pregnancy and neonatal outcome of babies delivered from HOM pregnancies obtained from the labor ward and theatre registers and neonatal unit records over a Byear period (April 2009-March 2012) were reviewed retrospectively.
Results Seventy-four babies (45, 24 and 5 triplets, quadruplets and quintuplets respectively) were delivered from $22 \mathrm{HOM}$ pregnancies out of 6521 deliveries giving a prevalence of 3.37/1000 total births. All deliveries were preterm and all the babies except 2 sets of triplets, 1 set and the $1^{\text {st }} 2$ of another set of quadruplets were delivered by caesarean section. The perinatal mortality rate was 243/1000 total births. Mortality was significantly increased with no antenatal booking (21/29 versus 5/45 for unbooked and booked pregnancies respectively, $\mathrm{p}=0.000)$, gestational age $\leq 30$ weeks $(21 / 25$ versus $5 / 49$ for gestational age $\leq 30$ weeks and $>30$ weeks respectively, $\mathrm{p}=0.000$ ) and birth weight $<1000 \mathrm{~g}$ for live births ( $8 / 56$ versus $10 / 10$ for birth weight $\geq 1000 \mathrm{gm}$ and $<1000 \mathrm{gm}$ respectively, $\mathrm{p}=0.000$ ).

Conclusion Proper antenatal care and close feto-maternal monitoring of HOM pregnancies will significantly reduce early preterm births and the resultant immediate poor outcomes for these pregnancies.

\section{THE INFLUENCE OF GESTATIONAL AGE ON THE EARLY MORBIDITY OF PRETERM INFANTS OF 32 TO 36 COMPLETED WEEKS OF GESTATION}

doi:10.1136/archdischild-2012-302724.1363

${ }^{1} \mathrm{AB}$ Scheuchenegger, ${ }^{2} \mathrm{E}$ Lechner, ${ }^{2} \mathrm{G}$ Wiesinger-Eidenberger, ${ }^{2} \mathrm{M}$ Weissensteiner, ${ }^{2} \mathrm{O}$ Wagner, ${ }^{1,3} \mathrm{~B}$ Resch. ${ }^{1}$ Research Unit for Neonatal Infectious Diseases and Epidemiology Medical University of Graz, Graz; ${ }^{2}$ Children's and Maternity Hospital Linz; Linz; ${ }^{3}$ Division of Neonatology, Department of Paediatrics, Medical University of Graz, Graz, Austria

Context Moderately preterm infants $(32+0$ to $36+6$ gestational weeks [GW]) account for an increasing proportion of prematurityassociated short-term morbidities; yet there is a relative paucity of data regarding neonatal outcome in this cohort.

Objective To determine the association between neonatal morbidity and gestational age and also maternal and perinatal complications with an adverse impact on the neonatal outcome.

Methods In this retrospective cohort study, preterm infants $(32+0$ to $36+6 \mathrm{GW}$ ) without congenital anomalies, born in the Children's and Maternity Hospital Linz between 2007 and June 2010, were included ( $\mathrm{n}=870)$. Data about all morbidities (respiratory and gastrointestinal problems, hypoglycemia, hyperbilirubinemia with phototherapy, length of stay in intensive care unit, other relevant problems) during their hospital stay. Stepwise regression analysis was used to determine significant associations between morbidity and the gestational age.

Results Overall, the incidence of morbidities increased from $24 \%$ at 36 weeks to $43 \%, 55 \%, 75 \%$ and $93 \%$ at 35, 34, 33 and 32 weeks, respectively. The most frequent morbidities were hyperbilirubinemia requiring a treatment (29\%) followed by respiratory (14\%) and gastrointestinal (14\%) problems. Less than $10 \%$ of the children had hypoglycemia; cerebral complications were rare. Lower gestational age was an independent risk factor for increased neonatal morbidity and longer hospital and NICU stays ( $p<0,001)$.

Conclusion Moderately preterm infants $(32+0-36+6 \mathrm{GW})$ are at higher risks for neonatal morbidities, and the lower the gestational age at birth is the higher is the risk for neonatal morbidities.

\section{CONSANGUINITY AND PREGNANCY OUTCOME}

doi:10.1136/archdischild-2012-302724.1364

BR Oandalji. Pediatrics, Ministry of Health, Amman, Jordan

Background and Aim Consanguinous marriage is common in Jordan and in middle east in general. the aim of the study was to seee the effect of consanguinity on pregnancy outcome in east Amman. (capital).

Patients and Methods Mothers in the post natal ward were interviewd and a special questionarre was filled. they were asked whether marriage was consanguinous or not, data was collected regarding no 
of pregnancies, abortions, still birth, \& intrauterine fetal death, multiple pregnancies, neonatal deaths, infant deaths, \& low birth weight babies.

Results The study included 190 mothers of consanguinous marriage and 320 non consanguinous. there was no statistically significant relation between consanguinity and no of pregnancies, abortions, stillbirths or multiple pregnancies.however there was a statistically significant relation between consanguinity and nneonatal deaths, infant deaths and low birth weight babies.

Conclusion Consanguinity has an adverse effect on pregnancy and neonatal outcome and should be considered as a factor in high risk pregnancy, the neonatologist and obstetrician should be alerted to.

\section{THE RELATIONSHIP BETWEEN MOTHER'S CONDITION AND NEWBORN BIRTH WEIGHT}

doi:10.1136/archdischild-2012-302724.1365

S Gatot-Irawan, A Sunardi, RP Rina-Pratiwi, A Agus-Fitrianto, MS Kosim. Department of Pediatrics, Faculty of Medicine Diponegoro University - Dr. Kariadi Hospital, Semarang, Indonesia

Background Birth weight is a powerful predictor of infant growth, intra uterine welfare and survival. The outcome of birth weight is a reasonable well-defined problem caused by factors that are potentially modifiable. Mother's condition were important risk factor for determining the outcome of birth weight.

Objective To determine the relationship between mother's condition and newborn birth weight

Methods/design Case control study in Dr. Kariadi Hospital Semarang, Indonesia. Data were taken from medical records of babies who fulfilled inclusion criteria and admitted from January 2011 until December 2011. The mother's condition included age, education, parity, nutritional status from Mid Upper Arm Circumference (MUAC), gestational age, antenatal care, (ANC), hypertension, and anaemia. Birth weight was determined at birth with same scale and categorized in to some categories. Statistical analyses used: $\mathrm{X}^{2}$ and logistic regression.

Results We obtained 30 mother of babies with low birth weight as a Case Group and 30 mother of babies/with appropriate birthweight as the control group. We found between groups: MUAC has (OR 0.10 ; 95\% CI:0.01-0.6) p=0.01, anaemia has (OR 0.13; 95\% CI :0.03$0.61) \mathrm{p}=0.09$, and gestational age has (OR 21.76; 95\% CI :3.6-129) $p=0,001$, age has (OR 0.90; 95\% CI :0.19-4.15) $p=0.89$, Hypertension has (OR 0.44; 95\% CI:0.73-2.69) $\mathrm{p}=0.37$, parity has (OR 0.36 ; 95\% CI:0.11-1.20) $\mathrm{p}=009$, education has (OR 0.12; 95\% CI :0.101.60) $\mathrm{p}=0.11$, ANC has (OR 0.01; 95\% CI :0.02-0.6) p=0.99.

Conclusion MUAC, anaemia and gestational age as risk factor of LBW. Gestational age was the most important one.

\section{PERINATAL RISK FACTORS OF INTRAUTERINE GROWTH RETARDATION}

doi:10.1136/archdischild-2012-302724.1366

'S Ali-Zade, 'S Huseynova, ${ }^{2} \mathrm{~N}$ Panakhova, ${ }^{2} \mathrm{~S}$ Hasanov, ${ }^{2} \mathrm{~S}$ Alasgarova, ${ }^{2} \mathrm{H}$ Dunyamaliyeva. ${ }^{1}$ Odlar Yurdu; ${ }^{2}$ Neonatology, Azerbaijan Medical University, Baku, Azerbaijan

Background and Aim Intrauterine growth retardation (IUGR) is a serious health condition that causes significant morbidity and serious developmental problems in children. The aim of this study was the identification of the role of pregnancy complications in the development of growth retardation.

Study Design 210 women with complicated pregnancy and their newborn infants were included in study. Pregnant women were classified depending on different pathologies such as preeclampsia, anemia, somatic diseases and their combinations. IUGR identified in infants whose estimated anthropometrical measurements was below the 10th percentile for its gestational age, and also confirmed using the Dubowitz/Ballard scale.

Results The IUGR was detected in $38.46 \%$ in women with different somatic diseases of pregnancy, in $50 \%$ in women with preeclampsia, $30.30 \%$ in women with different grade of anemia. Highest frequency (66.66\%) of this syndrom was diagnosed in infants whose mothers suffered from both preeclampsia and anemia during pregnancy, and in $33.3 \%$ of these infants determined symmetrical type growth restriction.

Conclusion Preeclampsia is one of the main factor affecting maternal-placental-fetal interactions and it may be accepted as more serious risk factor when associates with anemia in pregnancy.

\section{NEONATAL MOTALITY AND MOBIDITY RATES WHO WERE ADMITTED TO THE NEONATAL ICU OF KONYA IN TWO YEARS}

doi:10.1136/archdischild-2012-302724.1367

${ }^{1} \mathrm{H}$ Altunhan, ${ }^{2} \mathrm{~A}$ Annagür, ${ }^{3} Y U ̈$ Özdemir, ${ }^{3} \mathrm{M}$ Konak, ${ }^{3} \mathrm{R}$ Örs. ${ }^{1}$ Department of Neonatology, Abant Izzet Baysal University, Medical Faculty, Bolu; 'Department of Neonatology, Selcuk University, Selcuklu Medical Faculty; ${ }^{3}$ Department of Neonatology, Konya University, Meram Medical Faculty, Konya, Turkey

Objective Our purpose was to determine mortality and morbidity rates and selected outcome variables for infants especially weighing less than 1500 grams, who were admitted to the neonatal intensive care unit of our hospital from January 2007 to December 2008.

Material and Methods We evaluated infants who were admitted to the neonatal intensive care unit of our hospital (Konya University, Meram Medical Faculty) from January 2007 to December 2008. Results The percent of VLBW admissions to the our NICU was $14.3 \%$ in 2007 and $17.4 \%$ in 2008 . The mean birth weight and gestational age of the infants were 1027 \pm 308 grams (min-max: 400-1470gr), 28.3 \pm 3.8 weeks (min-max:22-36weeks) in 2007, 998 \pm 309 grams (min-max:400-1490gr), 28.4 \pm 3.4 weeks (minmax:22-36weeks) in 2008, respectively. Overall survival rate was $50 \%$ during two years. Respiratory support were given to $65 \%$ and 69.4\% VLBW newborns, in 2007 and 2008, respectively. Among selected outcomes, bronchopulmonary dysplasia, retinopathy of prematurity $(\mathrm{ROP})$, severe intraventricular hemorrhage (IVH), nosocomial infection, necrotizing enterocolitis(NEC), respiratory distress syndrome (RDS) were encountered in $1.66 \%, 4.6 \%, 1.9 \%$, $10.8 \%, 1.2 \%, 16.3 \%$ of the premature infants during two years, respectively.

Conclusion As a result the majority of neonatal deaths were due to complications of premature labor. Scientific and technological advances in Neonatology have led to increased rates of survival and long term morbidities in very low birth weight infants. Prevention of premature labor, sufficient antenatal maternal care and establishment of good delivery conditions to decrease neonatal infections and medical care after delivery could help to decrease neonatal mortality rates.

\section{PERINATAL MORTALITY RATE OF SELÇUK ÜNIVERSITY FACULTY OF MEDICIN IN YEAR OF 2008}

doi:10.1136/archdischild-2012-302724.1368

${ }^{1} \mathrm{H}$ Altunhan, ${ }^{2} \mathrm{~A}$ Annagür, ${ }^{3} Y U ̈$ Özdemir, ${ }^{3} \mathrm{M}$ Konak, ${ }^{3} \mathrm{R}$ Örs. ${ }^{1}$ Department of Neonatology, Abant lzzet Baysal University, Medical Faculty, Bolu; '2Department of Neonatology, Selcuk University, Selcuklu Medical Faculty; ${ }^{3}$ Department of Neonatology, Konya University, Meram Medical Faculty, Konya, Turkey

Objective Our purpose was to determine the perinatal mortality rate of our hospital in 2008. 